\title{
Interpersonal functioning deficits in association with DSM-IV personality disorder dimensions
}

\author{
Journal Article \\ Author(s): \\ Hengartner, Michael (1); Müller, Mario; Rodgers, Stephanie; Rössler, Wulf; AjdacicGross, Vladeta \\ Publication date: \\ 2014-02 \\ Permanent link: \\ https://doi.org/10.3929/ethz-b-000078032 \\ Rights / license: \\ In Copyright - Non-Commercial Use Permitted \\ Originally published in: \\ Social Psychiatry and Psychiatric Epidemiology 49(2), https://doi.org/10.1007/s00127-013-0707-x
}




\title{
Interpersonal functioning deficits in association with DSM-IV personality disorder dimensions
}

\author{
Michael P. Hengartner • Mario Müller • \\ Stephanie Rodgers · Wulf Rössler • \\ Vladeta Ajdacic-Gross
}

Received: 28 February 2013/Accepted: 2 May 2013/Published online: 15 May 2013

(C) Springer-Verlag Berlin Heidelberg 2013

\begin{abstract}
Purpose According to DSM, interpersonal functioning deficits are a main criterion for the general definition of personality disorders (PDs), but some PD diagnoses do not appear to be related to impaired interpersonal functioning. Social deficits have rarely been studied in all PD dimensions to date.

Methods We analyzed 511 adults aged 20-41 years from the general population of the canton of Zurich, Switzerland, using data from the Epidemiology Survey of the Zurich Programme for Sustainable Development of Mental Health Services (ZInEP). PD dimensions were measured with a questionnaire and indicators of interpersonal functioning with a semi-structured interview. Associations were analyzed with generalized linear models.

Results All PD dimensions were significantly associated with various indicators of interpersonal functioning deficits, such as distress and conflicts in friendships and partnership, feeling lonely, few close friends, and reduced social support. Schizotypal and borderline PD were relatively strongly associated with distress in friendships when compared with other PD dimensions. Furthermore, both dimensions were significantly related to all indicators of interpersonal functioning deficits.
\end{abstract}

\footnotetext{
M. P. Hengartner $(\bowtie) \cdot$ M. Müller · S. Rodgers · W. Rössler · V. Ajdacic-Gross

Department of Psychiatry, Psychotherapy and Psychosomatics, Zurich University Hospital of Psychiatry, PO Box 1930, 8021 Zurich, Switzerland

e-mail: michael.hengartner@dgsp.uzh.ch

W. Rössler

Collegium Helveticum, A Joint Research Institute Between the University of Zurich and the Swiss Federal Institute of

Technology, Zurich, Switzerland
}

Conclusions Subjects scoring high on any PD dimension reported considerable deficits in interpersonal functioning as characterized by a solitary lifestyle, conflictual and distressful social relations, and lack of social support. All DSM-IV PDs are associated with poor interpersonal functioning, but there is some evidence that schizotypal and borderline symptomatology affects deficits in social interactions even more profoundly and pervasively than other PD dimensions.

Keywords Interpersonal functioning - Functional impairment - Quality of life · Distress · Personality disorders · Social support · DSM-5 · Epidemiology

\section{Introduction}

Personality disorders (PDs) are persistent and pervasive patterns of inner experience and behaviour that impact interpersonal functioning. This conceptualization constitutes the general PD criterion of the operationalized diagnostic algorithm in DSM-IV-TR [1] and in the upcoming DSM-5 [2]. PDs are consequently by definition disorders of social interactions and interpersonal relations. In other words, subjects with pathological personality traits exhibit socio-culturally deviant interpersonal functioning. However, although conceptualized as a general PD criterion, interpersonal dysfunction is not readily found in some PD categories, in particular in histrionic or obsessive-compulsive PD. Thus, it is not surprising that clinicians rate the social impairment associated with the criterion for those two PDs as relatively low [3]. Support for this subjective appraisal is provided by Cramer et al. [4], who found that histrionic and obsessive-compulsive PDs were not related to significantly reduced global quality of life. In addition, 
Oltmanns et al. [5] found that histrionic PD was actually associated with higher social functioning, which is, considering the general criterion of interpersonal functioning deficits, a conflicting finding.

As explained above, interpersonal functioning is a fundamental factor of PDs, but has hardly been examined with respect to all $10 \mathrm{PD}$ dimensions to date. Various studies have reported that global psychosocial functioning is significantly impaired in subjects with PDs [4-9]. However, very few studies have examined specific aspects of interpersonal functioning. There is evidence that the negative effects of PD symptoms on interpersonal functioning play a role in separation and divorce $[6,10,11]$, lack of social support [4, 12], fewer close friends [5], and poorer interpersonal relationships $[4,13]$.

To better apprehend the consequences of PD symptomatology on interpersonal functioning, especially in PD dimensions other than borderline PD, more studies are required that extensively examine relationships and social behaviour in subjects with pathological personality. As Samuels [14] stated in a recent review, there is still a need for epidemiological studies of factors related to PDs in the general population. Thus, the aim of the present study was to expand the literature on interpersonal functioning in all 10 DSM-IV PD dimensions by specifically focusing on social behaviour, partnership, friendships, social network as well as social support in a large community sample of 20- to 41-year-old adults.

\section{Methods}

Study design and sampling

This study was conducted within the scope of the Epidemiology Survey of the Zurich Programme for Sustainable Development of Mental Health Services (ZInEP; in German: "Zürcher Impulsprogramm zur nachhaltigen Entwicklung der Psychiatrie"), a research and health care programme involving several psychiatric research divisions and mental health services of the canton of Zurich, Switzerland. The epidemiology survey is one of the six ZInEP subprojects and consists of four components: (1) a short telephone screening, (2) a comprehensive semi-structured face-to-face interview followed by self-report questionnaires, (3) tests in the sociophysiological laboratory, and (4) a longitudinal survey (see Fig. 1). The telephone screening and semi-structured interviews started in August 2010, the tests at the sociophysiological laboratory in February 2011, and the longitudinal survey in April 2011. The screening ended in May 2012 and all other components in September 2012.

First, a total of 9,829 Swiss males and females aged 20-41 years at the onset of the survey and considered

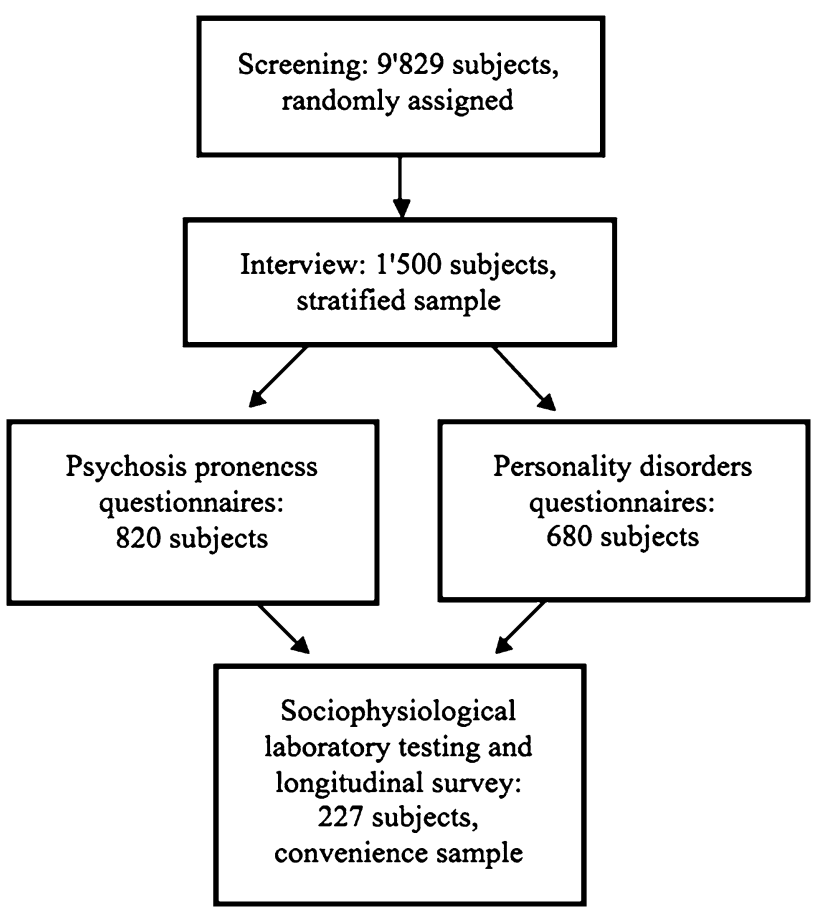

Fig. 1 The sampling procedure of the ZInEP Epidemiology Survey

representative of the general population of the canton of Zurich, Switzerland were screened by computer assisted telephone interview (CATI) using the Symptom Checklist 27 (SCL-27) [15]. All participants were randomly chosen through the resident registration offices of all municipalities of the canton of Zurich. Residents without Swiss nationality were excluded from the study. The CATI was conducted by GfK (Growth for Knowledge), a major market and field research institute, in accordance with instructions from the ZInEP research team. The overall response rate was $53.6 \%$. Reasons for non-response were no response, only telephone responder, incorrect telephone number, communication impossible, unavailability during the study period or refusal by a third person or the target person. In cases where potential subjects were available by telephone, the response rate was $73.9 \%$.

Second, 1,500 subjects were randomly selected from the initial screening sample for subsequent face-to-face interviews (response rate: $65.2 \%$ ). We applied a stratified sampling procedure including $60 \%$ high-scorers (scoring above the 75th percentile of the global severity index of the SCL-27) and $40 \%$ low-scorers (scoring below the 75th percentile of the global severity index). The basic sampling design was adapted from the longitudinal Zurich cohortstudy [16] and was chosen to enrich the sample with subjects at high-risk of mental disorders. Such a two-phase procedure with initial screening and subsequent interview with a stratified subsample is fairly common in epidemiological surveys [17]. 
Face-to-face interviews were conducted by experienced and extensively trained clinical psychologists. The interviews took place either at the participants' home or at the Psychiatric University Hospital in Zurich. All participants who completed the semi-structured interview were required to complete additional questionnaires. For this purpose, the sample was divided into subsamples focusing either on psychosis $(N=820)$ or on PDs $(N=680)$. Out of a total of 680 subjects in the PD subsample, 169 $(24.9 \%)$ refused to return or to complete all questionnaires required for the present study, resulting in a reduced final sample size of $N=511$ (284 females; 227 males).

The ZInEP epidemiology survey was approved by the Zurich State Ethical Committee (KEK) to fulfil all legal and data privacy protection requirements and is in strict accordance with the declaration of Helsinki of the World Medical Association. All participants gave their written informed consent.

\section{Instruments and measures}

To measure PD dimensions we used the Assessment of DSM-IV Personality Disorders Questionnaire (ADP-IV) [18]. The ADP-IV design allows a dimensional trait-score and a categorical PD diagnosis for each of the DSM-IV PDs. The ADP-IV is a paper-pencil self-report instrument consisting of 94 items which represent the 80 criteria of the 10 DSM-IV PD and the 14 research criteria of the depressive PD and the passive-aggressive PD. Each traitquestion is rated on a 7-point Likert scale, ranging from "totally disagree" to "totally agree". For the present study we used a German translation by Doering et al. [19]. Internal consistency of the ADP-IV dimensional PD scales is good [19, 20] and test-retest reliability and concurrent validity of the dimensional ADP-IV trait-scores are also satisfactory $[19,20]$. Most importantly, the ADP-IV showed good concordance with the SCID-II interview [21] and may be considered as an economic and valid alternative to semi-structured interviews.

All other variables included in the analysis were provided by the semi-structured interview, which was conducted using the "Structured Psychopathological Interview and Rating of the Social Consequences of Psychological Disturbances for Epidemiology" (SPIKE) [22]. This semistructured interview, developed for epidemiological surveys in psychiatric research, assesses data about sociodemography, somatic syndromes, psychopathology, substance use, medication, health services, impairment, and social activity. All variables of interpersonal functioning were taken from the sections on "demography" and "social network and partnership", which are two of the various sections included in the SPIKE. Each variable was assessed by a single question with standardized response options, except for number of close friends and relatives and the social support provided by them. The latter was assessed with a visual analogue scale ranging from 0 "no social support at all" to 10 "extensive social support". All participants who indicated that they had no partner were additionally asked whether they felt a need for more emotional warmth, which we defined as a proxy for loneliness. In contrast, participants who confirmed that they had a partner were asked if they experienced distress related to the partnership and how frequently severe conflicts with the partner occurred.

Statistical analysis

All associations between PD dimensions and psychosocial functioning were examined with a series of generalized linear models (GLM). PD dimensions were entered as the dependent variables. Because they were all right skewed, and after checking for the Akaike information criterion and the Bayesian information criterion, we fitted models with gamma distribution and log-link function. All continuous predictor variables were standardized using the z-transformation. All models were adjusted for age and sex. A robust estimator was used to reduce the effects of outliers and influential observations. Results were reported with unstandardized regression coefficients $(b)$ and their standard errors (SE). All analyses were performed with SPSS 20 for Macintosh.

\section{Results}

Because there were no substantial sex differences with respect to most PD dimensions and to increase the statistical power we just report the results unadjusted for sex. The three exceptions to that rule are indicated below. Associations between PD dimensions and interpersonal functioning are indicated in Tables 1, 2, 3. Paranoid PD was significantly related to living alone, having no children, being unmarried, distress in friendships, conflicts with friends, having no partner; and if there was a partner paranoid PD was associated with high distress and severe conflicts with the partner. Schizoid PD was significantly associated with living alone, distress in friendships, conflicts with friends, feeling lonely, having no partner, and distress in partnership. In contrast with all other PD dimensions schizoid PD was negatively related to feeling lonely, that is, subjects scoring high on the schizoid PD dimension indicated they felt less lonely. Schizotypal PD was significantly related to all nine predictors of interpersonal functioning. The association between schizotypal PD and distress in friendships was considerably strong (see Table 1). 
Table 1 Association between interpersonal functioning and Cluster A PD dimensions

\begin{tabular}{|c|c|c|c|c|c|c|}
\hline & Paranoid $b$ (SE) & Sig. & Schizoid $b$ (SE) & Sig. & Schizotypal $b$ (SE) & Sig. \\
\hline \multicolumn{7}{|l|}{ Living situation } \\
\hline Alone $(N=99)$ & $0.174(0.046)$ & 0.000 & $0.093(0.044)$ & 0.034 & $0.140(0.049)$ & 0.004 \\
\hline Community $(N=404)$ & Reference & & Reference & & Reference & \\
\hline \multicolumn{7}{|l|}{ Children } \\
\hline No $(N=389)$ & $0.181(0.051)$ & 0.000 & $0.052(0.048)$ & 0.277 & $0.123(0.050)$ & 0.014 \\
\hline Yes $(N=121)$ & Reference & & Reference & & Reference & \\
\hline \multicolumn{7}{|l|}{ Married } \\
\hline No $(N=371)$ & $0.190(0.050)$ & 0.000 & $0.072(0.044)$ & 0.099 & $0.134(0.048)$ & 0.006 \\
\hline Yes $(N=134)$ & Reference & & Reference & & Reference & \\
\hline \multicolumn{7}{|l|}{ Distress in friendships } \\
\hline High $(N=58)$ & $0.272(0.054)$ & 0.000 & $0.157(0.054)$ & 0.004 & $0.345(0.055)$ & 0.000 \\
\hline Moderate $(N=130)$ & $0.090(0.043)$ & 0.036 & $0.097(0.041)$ & 0.018 & $0.127(0.043)$ & 0.003 \\
\hline Low $(N=322)$ & Reference & & Reference & & Reference & \\
\hline \multicolumn{7}{|l|}{ Conflicts with friends } \\
\hline Severe $(N=26)$ & $0.303(0.087)$ & 0.000 & $0.202(0.075)$ & 0.007 & $0.312(0.081)$ & 0.000 \\
\hline Moderate $(N=101)$ & $0.057(0.046)$ & 0.218 & $0.076(0.044)$ & 0.087 & $0.144(0.046)$ & 0.002 \\
\hline No $(N=383)$ & Reference & & Reference & & Reference & \\
\hline \multicolumn{7}{|l|}{ Feeling lonely } \\
\hline Frequently $(N=42)$ & $0.129(0.090)$ & 0.151 & $-0.193(0.087)$ & 0.027 & $0.176(0.089)$ & 0.048 \\
\hline Sometimes $(N=81)$ & $-0.030(0.071)$ & 0.673 & $-0.162(0.070)$ & 0.022 & $0.010(0.072)$ & 0.885 \\
\hline Never $(N=48)$ & Reference & & Reference & & Reference & \\
\hline \multicolumn{7}{|l|}{ Partner } \\
\hline No $(N=171)$ & $0.180(0.040)$ & 0.000 & $0.198(0.037)$ & 0.000 & $0.217(0.041)$ & 0.000 \\
\hline Yes $(N=340)$ & Reference & & Reference & & Reference & \\
\hline \multicolumn{7}{|l|}{ Distress in partnership } \\
\hline High $(N=96)$ & $0.191(0.053)$ & 0.000 & $0.179(0.048)$ & 0.000 & $0.206(0.051)$ & 0.000 \\
\hline Moderate $(N=113)$ & $0.057(0.051)$ & 0.257 & $0.136(0.046)$ & 0.003 & $0.100(0.049)$ & 0.042 \\
\hline Low $(N=131)$ & Reference & & Reference & & Reference & \\
\hline \multicolumn{7}{|l|}{ Conflicts with partner } \\
\hline Severe $(N=39)$ & $0.162(0.069)$ & 0.019 & $0.123(0.071)$ & 0.086 & $0.186(0.068)$ & $\mathbf{0 . 0 0 7}$ \\
\hline Moderate $(N=155)$ & $-0.043(0.046)$ & 0.349 & $0.057(0.041)$ & 0.168 & $-0.001(0.045)$ & 0.974 \\
\hline No $(N=145)$ & Reference & & Reference & & Reference & \\
\hline
\end{tabular}

Bold values indicate statistical significance at $p<0.05$

Antisocial PD was significantly associated with having no children, being unmarried, distress in friendships and conflicts with friends, having no partner, and distress in partnership. One marked sex difference emerged: severe conflicts with partner was negatively related to antisocial PD in females $(b=-0.141, p=0.020)$, whereas in males it was highly positively related $(b=0.452, p<0.001)$. Borderline PD was significantly related to all nine indicators of interpersonal functioning. Furthermore, associations with distress in friendships, conflicts with friends, as well as feeling lonely were considerably higher than those found in other PD dimensions. Histrionic PD was significantly associated with all predictors of interpersonal functioning except for conflicts with partner. Finally, narcissistic PD was significantly related to living alone, having no children, being unmarried, distress in friendships and conflicts with friends, having no partner, and distress in partnership (see Table 2). With respect to narcissistic PD another sex difference emerged: high distress in partnership showed a substantial effect in females $(b=0.210$, $p<0.001)$, but not in males $(b=0.018, p=0.794)$.

Avoidant PD was significantly related to living alone, having no children, being unmarried, distress in friendships and conflicts with friends, and having no partner. Dependent PD was significantly related to living alone, having no children, distress in friendships as well as conflicts with friends, feeling lonely, and distress in partnership. Finally, obsessive-compulsive PD was significantly associated with living alone, distress in friendships and conflicts with friends, having no partner, and distress in partnership. The 
Table 2 Association between interpersonal functioning and Cluster B PD dimensions

\begin{tabular}{|c|c|c|c|c|c|c|c|c|}
\hline & Antisocial $b$ (SE) & Sig. & Borderline $b$ (SE) & Sig. & Histrionic $b$ (SE) & Sig. & Narcissistic $b$ (SE) & Sig. \\
\hline \multicolumn{9}{|l|}{ Living situation } \\
\hline Alone $(N=99)$ & $0.073(0.053)$ & 0.161 & $0.189(0.050)$ & 0.000 & $0.132(0.043)$ & 0.002 & $0.097(0.041)$ & 0.017 \\
\hline Community $(N=404)$ & Reference & & Reference & & Reference & & Reference & \\
\hline \multicolumn{9}{|l|}{ Children } \\
\hline No $(N=389)$ & $0.146(0.046)$ & 0.001 & $0.191(0.053)$ & 0.000 & $0.181(0.046)$ & 0.000 & $0.089(0.045)$ & 0.047 \\
\hline Yes $(N=121)$ & Reference & & Reference & & Reference & & Reference & \\
\hline \multicolumn{9}{|l|}{ Married } \\
\hline No $(N=371)$ & $0.138(0.043)$ & 0.001 & $0.160(0.053)$ & 0.002 & $0.126(0.046)$ & 0.005 & $0.093(0.043)$ & 0.032 \\
\hline Yes $(N=134)$ & Reference & & Reference & & Reference & & Reference & \\
\hline \multicolumn{9}{|l|}{ Distress in friendships } \\
\hline High $(N=58)$ & $0.241(0.069)$ & 0.000 & $0.365(0.060)$ & 0.000 & $0.296(0.053)$ & 0.000 & $0.198(0.050)$ & 0.000 \\
\hline Moderate $(N=130)$ & $0.130(0.042)$ & 0.002 & $0.141(0.046)$ & 0.002 & $0.114(0.039)$ & 0.003 & $0.057(0.037)$ & 0.116 \\
\hline Low $(N=322)$ & Reference & & Reference & & Reference & & Reference & \\
\hline \multicolumn{9}{|l|}{ Conflicts with friends } \\
\hline Severe $(N=26)$ & $0.278(0.076)$ & 0.000 & $0.366(0.075)$ & 0.000 & $0.220(0.067)$ & 0.001 & $0.164(0.074)$ & 0.026 \\
\hline Moderate $(N=101)$ & $0.163(0.051)$ & 0.001 & $0.069(0.050)$ & 0.167 & $0.093(0.042)$ & 0.027 & $0.071(0.040)$ & 0.078 \\
\hline No $(N=383)$ & Reference & & Reference & & Reference & & Reference & \\
\hline \multicolumn{9}{|l|}{ Feeling lonely } \\
\hline Frequently $(N=42)$ & $0.131(0.103)$ & 0.203 & $0.354(0.095)$ & 0.000 & $0.207(0.085)$ & 0.015 & $0.100(0.083)$ & 0.227 \\
\hline Sometimes $(N=81)$ & $0.012(0.073)$ & 0.872 & $0.138(0.075)$ & 0.066 & $0.115(0.065)$ & 0.077 & $0.057(0.069)$ & 0.409 \\
\hline Never $(N=48)$ & Reference & & Reference & & Reference & & Reference & \\
\hline \multicolumn{9}{|l|}{ Partner } \\
\hline No $(N=171)$ & $0.138(0.043)$ & 0.001 & $0.163(0.045)$ & 0.000 & $0.107(0.039)$ & 0.007 & $0.128(0.035)$ & 0.000 \\
\hline Yes $(N=340)$ & Reference & & Reference & & Reference & & Reference & \\
\hline \multicolumn{9}{|l|}{ Distress in partnership } \\
\hline High $(N=96)$ & $0.148(0.056)$ & 0.009 & $0.238(\mathbf{0 . 0 5 8})$ & 0.000 & $0.171(\mathbf{0 . 0 5 0})$ & 0.001 & $0.132(0.043)$ & 0.002 \\
\hline Moderate $(N=113)$ & $0.064(0.046)$ & 0.165 & $0.055(0.055)$ & 0.316 & $0.057(0.048)$ & 0.236 & $0.110(0.044)$ & 0.013 \\
\hline Low $(N=131)$ & Reference & & Reference & & Reference & & Reference & \\
\hline \multicolumn{9}{|l|}{ Conflicts with partner } \\
\hline Severe $(N=39)$ & $0.115(0.085)$ & 0.177 & $0.171(0.076)$ & 0.024 & $0.108(0.064)$ & 0.092 & $0.111(0.059)$ & 0.059 \\
\hline Moderate $(N=155)$ & $-0.002(0.043)$ & 0.954 & $-0.002(0.051)$ & 0.973 & $-0.024(0.045)$ & 0.596 & $0.000(0.039)$ & 0.991 \\
\hline No $(\mathrm{N}=145)$ & Reference & & Reference & & Reference & & Reference & \\
\hline
\end{tabular}

Bold values indicate statistical significance at $p<0.05$

total score, which is a sum-score of all 10 PD dimensions, was significantly related to all indicators except for feeling lonely and conflicts with partner (see Table 3).

Associations between PD dimensions and the social network as a proxy of interpersonal functioning are reported in Table 4. Paranoid, schizotypal, borderline, narcissistic, avoidant, dependent, and obsessive-compulsive PDs as well as the total PD score were significantly negatively related to the number of close friends and relatives and the social support provided by them. Importantly, narcissistic PD was significantly related to social support by friends only in females $(b=-0.091$, $p<0.001)$, but not in males $(b=0.003, p=0.900)$. Schizoid PD was negatively associated with social support from friends and relatives and number of close relatives.
Antisocial PD was significantly negatively associated with the number of close relatives, whereas histrionic PD was negatively related to the number of close friends and relatives, but only to the social support provided by relatives.

\section{Discussion}

In this study, we examined interpersonal functioning in association with dimensional trait-scores of all 10 DSM-IV PDs, using data from a large community sample of 20-41 year-old adults. To the best of our knowledge, this is the first study that has focused specifically on various indicators of social behaviour and social support in all 10 DSM-IV PDs using data from the general population. In 
Table 3 Association between interpersonal functioning and Cluster C PD dimensions

\begin{tabular}{|c|c|c|c|c|c|c|c|c|}
\hline & Avoidant $b$ (SE) & Sig. & Dependent $b$ (SE) & Sig. & Obs.-comp. $b$ (SE) & Sig. & Total score $b$ (SE) & Sig. \\
\hline \multicolumn{9}{|l|}{ Living situation } \\
\hline Alone $(N=99)$ & $0.168(0.050)$ & 0.001 & $0.099(0.044)$ & 0.026 & $0.077(\mathbf{0 . 0 3 5})$ & 0.027 & $0.128(0.035)$ & 0.000 \\
\hline Community $(N=404)$ & Reference & & Reference & & Reference & & Reference & \\
\hline \multicolumn{9}{|l|}{ Children } \\
\hline No $(N=389)$ & $0.215(0.053)$ & 0.000 & $0.130(0.048)$ & 0.007 & $0.070(0.042)$ & 0.095 & $0.137(\mathbf{0 . 0 3 8})$ & 0.000 \\
\hline Yes $(N=121)$ & Reference & & Reference & & Reference & & Reference & \\
\hline \multicolumn{9}{|l|}{ Married } \\
\hline No $(N=371)$ & $0.153(0.054)$ & 0.004 & $0.072(0.049)$ & 0.146 & $0.061(0.040)$ & 0.128 & $0.120(0.037)$ & 0.001 \\
\hline Yes $(N=134)$ & Reference & & Reference & & Reference & & Reference & \\
\hline \multicolumn{9}{|l|}{ Distress in friendships } \\
\hline High $(N=58)$ & $0.290(0.063)$ & 0.000 & $0.262(0.056)$ & 0.000 & $0.167(0.043)$ & 0.000 & $0.258(0.042)$ & 0.000 \\
\hline Moderate $(N=130)$ & $0.108(0.048)$ & 0.024 & $0.075(0.041)$ & 0.069 & $0.044(0.036)$ & 0.215 & $0.096(0.032)$ & 0.003 \\
\hline Low $(N=322)$ & Reference & & Reference & & Reference & & Reference & \\
\hline \multicolumn{9}{|l|}{ Conflicts with friends } \\
\hline Severe $(N=26)$ & $0.324(0.081)$ & 0.000 & $0.173(\mathbf{0 . 0 6 3})$ & 0.006 & $0.165(0.050)$ & 0.001 & $0.251(0.056)$ & 0.000 \\
\hline Moderate $(N=101)$ & $0.034(0.049)$ & 0.486 & $0.001(0.045)$ & 0.986 & $0.059(0.039)$ & 0.125 & $0.073(\mathbf{0 . 0 3 5})$ & 0.038 \\
\hline No $(N=383)$ & Reference & & Reference & & Reference & & Reference & \\
\hline \multicolumn{9}{|l|}{ Feeling lonely } \\
\hline Frequently $(N=42)$ & $0.080(0.098)$ & 0.418 & $0.256(0.081)$ & 0.002 & $0.067(0.074)$ & 0.366 & $0.126(0.067)$ & 0.061 \\
\hline Sometimes $(N=81)$ & $0.014(0.079)$ & 0.863 & $0.131(0.068)$ & 0.053 & $0.077(0.059)$ & 0.187 & $0.033(0.050)$ & 0.511 \\
\hline Never $(N=48)$ & Reference & & Reference & & Reference & & Reference & \\
\hline \multicolumn{9}{|l|}{ Partner } \\
\hline No $(N=171)$ & $0.192(0.045)$ & 0.000 & $0.067(0.040)$ & 0.094 & $0.065(0.032)$ & 0.044 & $0.144(0.030)$ & 0.000 \\
\hline Yes $(N=340)$ & Reference & & Reference & & Reference & & Reference & \\
\hline \multicolumn{9}{|l|}{ Distress in partnership } \\
\hline High $(N=96)$ & $0.097(0.066)$ & 0.143 & $0.156(0.054)$ & 0.004 & $0.152(0.042)$ & 0.000 & $0.170(0.040)$ & 0.000 \\
\hline Moderate $(N=113)$ & $0.059(0.057)$ & 0.299 & $0.108(0.051)$ & 0.036 & $0.116(0.044)$ & 0.009 & $0.093(\mathbf{0 . 0 3 8})$ & 0.014 \\
\hline Low $(N=131)$ & Reference & & Reference & & Reference & & Reference & \\
\hline \multicolumn{9}{|l|}{ Conflicts with partner } \\
\hline Severe $(N=39)$ & $0.006(0.099)$ & 0.951 & $-0.023(0.066)$ & 0.726 & $0.092(0.055)$ & 0.097 & $0.103(0.056)$ & 0.066 \\
\hline Moderate $(N=155)$ & $-0.068(0.052)$ & 0.188 & $0.006(0.048)$ & 0.905 & $0.040(0.039)$ & 0.302 & $-0.005(0.035)$ & 0.891 \\
\hline No $(N=145)$ & Reference & & Reference & & Reference & & Reference & \\
\hline
\end{tabular}

Bold values indicate statistical significance at $p<0.05$

sum, the results showed that general personality pathology was associated with living alone, having no children, being unmarried, having considerable distress and conflicts with friends, feeling lonely (except for schizoid PD), and having no partner. Living in a committed partnership and scoring high on any PD dimension except for avoidant PD was associated with high relationship distress. Rather surprisingly, severe conflicts with a partner were uniquely associated with paranoid, schizotypal, and borderline PD. The number of close friends and relatives or the social support provided by them was negatively related to all PD dimensions. Every PD dimension was significantly associated with the majority of indicators of interpersonal functioning deficits, indicating a pervasive and consistent effect.
We conclude from our data that general personality maladjustment is highly indicative of a rather detached and solitary lifestyle without partner and children, conflictual and disturbed interpersonal relations, few close friends and relatives, and lack of social support. Consequently, all 10 DSM-IV PDs are characterised by rather high psychosocial distress and functional impairment. These findings are mostly in line with the literature [4-9]. However, our results conflict with an association between social functioning specifically reported for histrionic PD. In contrast to Oltmanns et al. [5] who reported a positive association, we found a consistent negative association between histrionic PD and interpersonal functioning. However, as the authors state in their discussion of this particular finding, they doubt that histrionic subjects exhibit better social 
Table 4 Association between social network and PD dimensions

\begin{tabular}{|c|c|c|c|c|c|c|c|c|}
\hline & \multicolumn{2}{|c|}{ Number of close friends } & \multicolumn{2}{|c|}{ Social support friends } & \multicolumn{2}{|c|}{ Number of close relatives } & \multicolumn{2}{|c|}{ Social support relatives } \\
\hline & $b(\mathrm{SE})$ & Sig & $b(\mathrm{SE})$ & Sig & $b(\mathrm{SE})$ & Sig & $b(\mathrm{SE})$ & Sig \\
\hline Paranoid PD & $-0.091(0.020)$ & 0.000 & $-0.073(0.018)$ & 0.000 & $-0.070(0.026)$ & 0.007 & $-0.047(0.018)$ & 0.008 \\
\hline Schizoid PD & $-0.049(0.038)$ & 0.191 & $-0.096(0.017)$ & 0.000 & $-0.044(0.018)$ & 0.012 & $-0.048(0.016)$ & 0.003 \\
\hline Schizotypal PD & $-0.090(0.025)$ & 0.000 & $-0.071(0.018)$ & 0.000 & $-0.078(0.023)$ & 0.001 & $-0.048(0.017)$ & 0.005 \\
\hline Antisocial PD & $-0.019(0.016)$ & 0.215 & $-0.009(0.019)$ & 0.616 & $-0.054(0.020)$ & 0.007 & $-0.034(0.018)$ & 0.054 \\
\hline Borderline PD & $-0.088(0.025)$ & 0.001 & $-0.055(0.018)$ & 0.003 & $-0.109(0.021)$ & 0.000 & $-0.072(0.018)$ & 0.000 \\
\hline Histrionic PD & $-0.056(0.016)$ & 0.001 & $-0.028(0.016)$ & 0.089 & $-0.067(0.018)$ & 0.000 & $-0.035(0.015)$ & 0.024 \\
\hline Narcissistic PD & $-0.048(0.017)$ & 0.005 & $-0.050(0.016)$ & 0.001 & $-0.066(0.017)$ & 0.000 & $-0.033(0.015)$ & 0.027 \\
\hline Avoidant PD & $-0.104(0.026)$ & 0.000 & $-0.108(0.020)$ & 0.000 & $-0.089(0.024)$ & 0.000 & $-0.088(0.020)$ & 0.000 \\
\hline Dependent PD & $-0.059(0.021)$ & 0.004 & $-0.079(0.017)$ & 0.000 & $-0.053(0.018)$ & 0.003 & $-0.054(0.016)$ & 0.001 \\
\hline Obs.-comp. PD & $-0.062(0.016)$ & 0.000 & $-0.063(0.014)$ & 0.000 & $-0.054(0.019)$ & 0.004 & $-0.051(0.014)$ & 0.000 \\
\hline Total score & $-0.067(0.019)$ & 0.000 & $-0.069(0.014)$ & 0.000 & $-0.069(0.017)$ & 0.000 & $-0.054(0.013)$ & 0.000 \\
\hline
\end{tabular}

Bold values indicate statistical significance at $p<0.05$

functioning. Instead, they attribute the positive association found in their data to a methodological artefact based on the questionnaire they applied, which included questions such as "how many times in the last 2 weeks have you gone out socially with other people" or "how many friends have you seen or been in contact with in the last two weeks?". In agreement with Oltmanns et al. [5] we consider such measures as rather weak indicators of interpersonal functioning deficits-especially in relation with histrionic PD, which is characterized by superficial relationships - and suggest that questions that directly assess conflicts and distress in relationships, as provided in the present study, are more valid indicators of social dysfunction. Finally, in contrast to Cramer et al. [4], our results suggest that both histrionic and obsessive-compulsive PDs are significantly related to reduced quality of life, given that interpersonal functioning is a crucial indicator of quality of life.

Schizotypal and borderline PD were the only dimensions that were significantly related to all predictors and the only disorders that showed some considerably strong associations relative to other PD dimensions. This is in accordance with other studies, which have found that psychosocial and functional impairment is more severe, persistent and enduring in patients with schizotypal, and in particular, borderline PD compared with other PD diagnoses [9, 23, 24]. Consequently, it seems that associations with social factors are particularly strong in schizotypal and borderline PD, which we have also recently demonstrated with respect to childhood adversity [25].

Some studies suggest that psychosocial and functional impairment is more severe, persistent and enduring in patients with PDs than, for instance, in subjects with major depression [9, 13, 23]. Skodol et al. [9] state that impairment in social relationships appears to be highly stable over time in subjects with PDs. Furthermore, it has been shown that co-occurring PDs significantly increase impairment in social functioning in patients with mood disorders [26-28]. Thus, interpersonal dysfunction is a very serious issue in subjects with pathological personality traits. This assumption is supported by an Italian study which found that among diagnoses of schizophrenia, affective disorder and PD only the latter accounted for reduced quality of social relations when adjusted for various covariates [29]. Further evidence is provided by two other studies, which found that PDs significantly reduced the subjective quality of life [4, 30]. Soeteman et al. [30] additionally showed that the quality of life was inversely related to the number of comorbid PD diagnoses and that the quality of life in PD patients was comparable to that of patients with lung cancer or Parkinson's disease. This is in accordance with our data, where the total PD score was significantly related to most indicators of social functioning. That finding indicates that social dysfunction increases with the accumulation of additional PD symptoms.

Despite the strengths of a large community sample and careful and elaborate assessment of interpersonal functioning in association with all 10 DSM-IV PDs, this study is also subject to one major limitation. Because of the cross-sectional design we cannot draw causal conclusions from our data. It could be that interpersonal functioning has an effect on PD symptoms, or vice versa. However, since PDs usually originate in early adolescence and are rather stable and enduring conditions over time [31], it is more plausible that PD symptoms preceded our indicators of interpersonal functioning. It makes intuitively more sense to conclude that subjects are unmarried, have no children and experience more distress and conflicts in their relationships because they have pathological personality traits, and not the other way round. In addition we acknowledge 
the reduced response rate. Assuming that more severely ill people are harder to access and less willing to participate, we cannot exclude a bias in this respect. Furthermore, all data in the present study relied on self-reports, which means that our results may be biased through omission, denial, or concealment.

In conclusion, in this study we addressed an important issue of PD research that has hardly been examined before. Although a main criterion for PD diagnosis [1] very few studies have specifically examined interpersonal functioning deficits in all PDs. In this respect, we found that subjects scoring high on any PD dimension reported considerable deficits in interpersonal functioning, as characterized through a solitary lifestyle, conflictual and distressful social relations, and a lack of social support. All DSM-IV PDs are associated with poor interpersonal functioning, but there is some evidence that schizotypal and in particular borderline symptomatology affects deficits in social interactions even more profoundly than other PD dimensions. These deficits have detrimental effects on the quality of life and a serious impact on public mental health policies [14, 32, 33].

Acknowledgments ZInEP was supported by a private donation. The donor had no further role in the experimental design, the collection, analysis, and interpretation of data, the writing of this report, or the decision to submit this paper for publication.

Conflict of interest On behalf of all authors, the corresponding author states that there is no conflict of interest.

\section{References}

1. American Psychiatric Association (2000) Diagnostic and Statistical Manual of Mental Disorders DSM-IV-TR, 4th text revision edn. American Psychiatric Association, Washington, DC

2. American Psychiatric Association (2013) Diagnostic and statistical manual of mental disorders DSM-5. American Psychiatric Association, Washington, DC

3. Funtowicz MN, Widiger TA (1999) Sex bias in the diagnosis of personality disorders: an evaluation of the DSM-IV criteria. J Abnorm Psychol 108:195-201

4. Cramer V, Torgersen S, Kringlen E (2006) Personality disorders and quality of life. A population study. Compr Psychiatry $47: 178-184$

5. Oltmanns TF, Melley AH, Turkheimer E (2002) Impaired social functioning and symptoms of personality disorders assessed by peer and self-report in a nonclinical population. J Pers Disord $16: 437-452$

6. Grant BF, Hasin DS, Stinson FS, Dawson DA, Chou SP, Ruan WJ, Pickering RP (2004) Prevalence, correlates, and disability of personality disorders in the United States: results from the national epidemiologic survey on alcohol and related conditions. J Clin Psychiatry 65:948-958

7. Jackson HJ, Burgess PM (2000) Personality disorders in the community: a report from the Australian National Survey of Mental Health and Wellbeing. Soc Psychiatry Psychiatr Epidemiol 35:531-538
8. Narud K, Mykletun A, Dahl AA (2005) Quality of life in patients with personality disorders seen at an ordinary psychiatric outpatient clinic. BMC Psychiatry 5:10

9. Skodol AE, Pagano ME, Bender DS, Shea MT, Gunderson JG, Yen S, Stout RL et al (2005) Stability of functional impairment in patients with schizotypal, borderline, avoidant, or obsessivecompulsive personality disorder over two years. Psychol Med $35: 443-451$

10. Coid J, Yang M, Tyrer P, Roberts A, Ullrich S (2006) Prevalence and correlates of personality disorder in Great Britain. Br J Psychiatry 188:423-431

11. Samuels J, Nestadt G, Romanoski AJ, Folstein MF, McHugh PR (1994) DSM-III personality disorders in the community. Am J Psychiatry 151:1055-1062

12. Ekselius L, Tillfors M, Furmark T, Fredrikson M (2001) Personality disorders in the general population: DSM-IV and ICD-10 defined prevalence as related to sociodemographic profile. Pers Individ Differ 30:311-320

13. Skodol AE, Gunderson JG, McGlashan TH, Dyck IR, Stout RL, Bender DS, Grilo CM et al (2002) Functional impairment in patients with schizotypal, borderline, avoidant, or obsessive-compulsive personality disorder. Am J Psychiatry 159: 276-283

14. Samuels J (2011) Personality disorders: epidemiology and public health issues. Int Rev Psychiatry 23:223-233

15. Hardt J, Egle UT, Kappis B, Hessel A, Brahler E (2004) Symptom checklist SCL-27: results of a representative German survey. Psychother Psychosom Med Psychol 54:214-223

16. Angst J, Gamma A, Neuenschwander M, Ajdacic-Gross V, Eich D, Rössler W, Merikangas KR (2005) Prevalence of mental disorders in the Zurich cohort study: a twenty year prospective study. Epidemiol Psichiatr Soc 14:68-76

17. Dunn G, Pickles A, Tansella M, Vazquez-Barquero JL (1999) Two-phase epidemiological surveys in psychiatric research. Br J Psychiatry 174:95-100

18. Schotte CKW, de Doncker D (1994) ADP-IV questionnaire. University Hospital Antwerp, Antwerp

19. Doering S, Renn D, Hofer S, Rumpold G, Smrekar U, Janecke N, Schatz DS et al (2007) Validation of the German version of the assessment of DSM-IV personality disorders (ADP-IV) questionnaire. Z Psychosom Med Psychother 53:111-128

20. Schotte CKW, de Doncker D, Vankerckhoven C, Vertommen H, Cosyns P (1998) Self-report assessment of the DSM-IV personality disorders. Measurement of trait and distress characteristics: the ADP-IV. Psychol Med 28:1179-1188

21. Schotte CKW, de Doncker DA, Dmitruk D, Van Mulders I, D'Haenen H, Cosyns P (2004) The ADP-IV questionnaire: differential validity and concordance with the semi-structured interview. J Pers Disord 18:405-419

22. Angst J, Dobler-Mikola A, Binder J (1984) The Zurich study-a prospective epidemiological study of depressive, neurotic and psychosomatic syndromes. I. Problem, methodology. Eur Arch Psychiatry Neurol Sci 234:13-20

23. Gunderson JG, Stout RL, McGlashan TH, Shea MT, Morey LC, Grilo CM, Zanarini MC et al (2011) Ten-year course of borderline personality disorder: psychopathology and function from the collaborative longitudinal personality disorders study. Arch Gen Psychiatry 68:827-837

24. Zanarini MC, Frankenburg FR, Reich DB, Fitzmaurice G (2010) The 10-year course of psychosocial functioning among patients with borderline personality disorder and axis II comparison subjects. Acta Psychiatr Scand 122:103-109

25. Hengartner MP, Ajdacic-Gross V, Rodgers S, Müller M, Rössler W (2013) Childhood adversity in association with personality disorder dimensions: new findings in an old debate. Eur Psychiatry (in press) 
26. Carpenter D, Clarkin JF, Glick ID, Wilner PJ (1995) Personality pathology among married adults with bipolar disorder. J Affect Disord 34:269-274

27. Leader JB, Klein DN (1996) Social adjustment in dysthymia, double depression and episodic major depression. J Affect Disord 37:91-101

28. Skodol AE, Grilo CM, Pagano ME, Bender DS, Gunderson JG, Shea MT, Yen S et al (2005) Effects of personality disorders on functioning and well-being in major depressive disorder. J Psychiatr Pract 11:363-368

29. Ruggeri M, Gater R, Bisoffi G, Barbui C, Tansella M (2002) Determinants of subjective quality of life in patients attending community-based mental health services. The South-Verona Outcome Project 5. Acta Psychiatr Scand 105:131-140

30. Soeteman DI, Verheul R, Busschbach JJ (2008) The burden of disease in personality disorders: diagnosis-specific quality of life. J Pers Disord 22:259-268
31. Johnson JG, Cohen P, Kasen S, Skodol AE, Brook J (2000) Agerelated change in personality disorder symptom levels between early adolescence and adulthood: a community-based longitudinal investigation. Acta Psychiatr Scand 102:265-275

32. ten Have M, Iedema J, Ormel J, Vollebergh W (2006) Explaining service use for mental health problems in the Dutch general population: the role of resources, emotional disorder and functional impairment. Soc Psychiatry Psychiatr Epidemiol 41:285-293

33. Swanson J, Swartz M, Estroff S, Borum R, Wagner R, Hiday V (1998) Psychiatric impairment, social contact, and violent behavior: evidence from a study of outpatient-committed persons with severe mental disorder. Soc Psychiatry Psychiatr Epidemiol 33(Suppl 1):S86-S94 